\title{
SECONDARY CAST AL-ALLOYS WITH HIGHER CONTENT OF IRON
}

\author{
Denisa Závodská ${ }^{1}$, Eva Tillová ${ }^{1}$, Ivana Švecová ${ }^{1}$, Lenka Kuchariková ${ }^{1}$, Mária Chalupová ${ }^{1}$ \\ 1 University of Žilina, Faculty of Mechanical Engineering, Univerzitná 8215/1, 01026 Žilina, Slovakia. \\ e-mail: denisa.zavodska@fstroj.uniza.sk
}

\section{Introduction}

Recycling aluminum alloys provides major economic benefits. Recycling aluminum scrap results in the production of only $5 \%$ of the carbon dioxide produced in making new primary metal. Thus, the energy savings of recycling aluminum also translates into reduced environmental emissions [1].

Recycled aluminium is produced from both new and old scrap. New scrap is surplus material that arises during the production, fabrication and manufacture of Al-products up to the point where they are sold to the final consumer. The production route of new scrap from collection to recycled metal is thus controlled by the Al-industry. Old scrap is Al-material that is treated and melted down after an existing Al-product has been used, discarded and collected. Based on statistics and existing knowledge of the European Al-scrap flow (excluding internal scrap), approximately $40 \%$ of recycled Al-originates from old scrap, and the rest is new scrap [2].

With increasing recycled scraps, mixing and thickening impurity elements in the recycling of aluminum alloy components lead to a serious problem, because the cast components are expected to exhibit their higher performance. That is a reason why virgin ingots containing low iron as an impurity element are supplied to some of highly secured automotive components, instead of manufacturing with recycled ingots. Typical products made from recycled aluminium include castings like cylinder heads, engine blocks, gearboxes and many other automotive and engineering components on the one hand, and extrusion billets or rolling ingots for the production of profiles, sheets, strips and foil on the other [3].

The present study is part of a larger research project which was conducted to study of secondary Al-Si cast alloys. The article describes the evaluation of porosity in secondary AlSi7Mg0.3 cast alloys with major amount of iron.

\section{Experimental part}

Experimental material was secondary unmodified AlSi7Mg0.3 cast alloy with chemical composition (in weight \%): alloy A - $0.036 \mathrm{Zn}$; $7.028 \%$ Si; $0.013 \%$ Cu; $\mathbf{0 . 1 2 3}$ \% Fe; $0.009 \%$ Mn; $0.354 \% \mathrm{Mg} ; 0.123 \% \mathrm{Ti} ; 0.002 \% \mathrm{Ni} ; 0.002$ \% Cr; 0.0003 \% Bi; $0.0007 \%$ Sb; rest - Al; alloy B - $0.020 \mathrm{Zn} ; 7.340$ \% Si; $0.021 \%$ Cu; $\mathbf{0 . 4 5 4 ~ \% ~ F e ; ~}$ $0.009 \% \mathrm{Mn} ; 0.302 \% \mathrm{Mg} ; 0.118 \% \mathrm{Ti} ; 0.002 \%$ $\mathrm{Ni} ; 0.002 \% \mathrm{Cr} ; 0.0003 \% \mathrm{Bi}$; 0.0007\% Sb; rest $\mathrm{Al}$; alloy C - $0.028 \mathrm{Zn} ; 7.315 \% \mathrm{Si} ; 0.030 \%$ $\mathrm{Cu} ; \underline{\mathbf{0 . 6 5 5} \%} \mathbf{\text { Fe}} ; 0.0010 \% \mathrm{Mn} ; 0.292 \%$ Mg; $0.118 \%$ Ti; $0.002 \%$ Ni; 0.002 \% Cr; $0.0003 \%$ Bi; $0.0007 \% \mathrm{Sb}$; rest - Al; with good casting properties, very good machining, wear resistance and with low thermal expansion. This experimental alloy have the widest application in mechanical, electrical vehicles and aviation engineering, wheels, parts requiring good electrical conductivity and high strength, etc.

Test bars were produced by process such as sand casting in UNEKO, Zátor, Ltd. Czech Republic with diameters ø $20 \mathrm{~mm}$, length $300 \mathrm{~mm}$. Sand casting is the easiest and the most common used casting method. The melt was not modified or refined. We used casted bars without any heat treatment. Metallographic samples were sectioned from these casted bars and they were standard prepared for metallographic observation (wet ground on $\mathrm{SiC}$ paper, DP polished with $3 \mu \mathrm{m}$ diamond past followed by Struers Op-S and etched by $\mathrm{H}_{2} \mathrm{SO}_{4}$ ). Quantitative metallography was carried out on an Image Analyzer NIS - Elements 4.2 to quantify amount and size of pores as determination of average values [4].

\begin{tabular}{|l|c|c|c|}
\hline wt. \% of Fe & $\mathbf{0 . 1 2 3}$ & $\mathbf{0 . 4 5 4}$ & $\mathbf{0 . 6 5 5}$ \\
\hline Pore size; $\mu \mathrm{m}^{2}$ & 20878 & 16031 & 18781 \\
\hline
\end{tabular}

Tab. 1. Influence of iron on porosity

The total results in average of the pores sizes with different \% of iron are evaluated in Tab. 1 and documented in Fig. 1. 


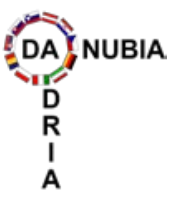

34th Danubia-Adria Symposium on Advances in Experimental Mechanics

University of Trieste, Italy, 2017
Porosity is directly proportional with \% Fe. First, as the iron content increases, the total porosity values of extended-defect formation at high iron levels during stage initially decrease (from cca $20878 \mu^{2}$ to $16031 \mu^{2}$ ), until a minimum value is reached at $0.454 \%$, it was not known if the minimum total porosity would \% Fe, after which further increases in iron result in increased occur at $0.4 \%$. These results are in accord with works [5] and [6]. As further iron of additions are made, the overall porosity level increases.

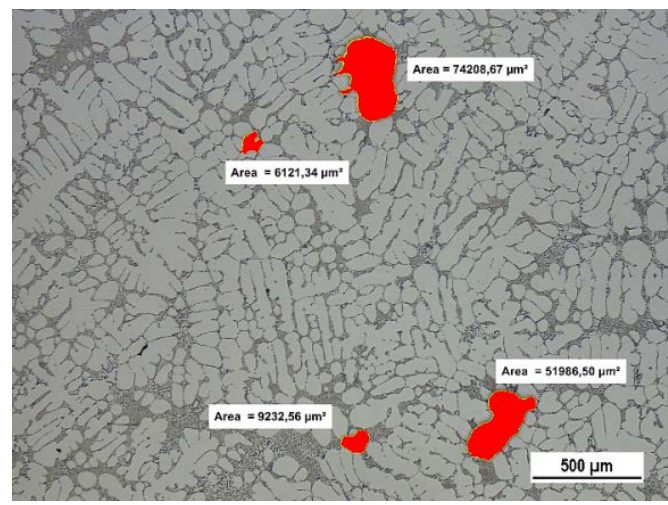

a) $0.123 \% \mathrm{Fe}$.

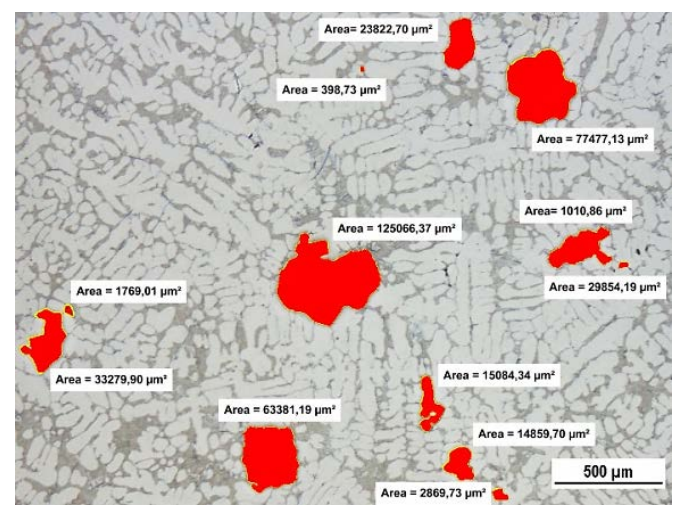

b) $0.454 \% \mathrm{Fe}$.

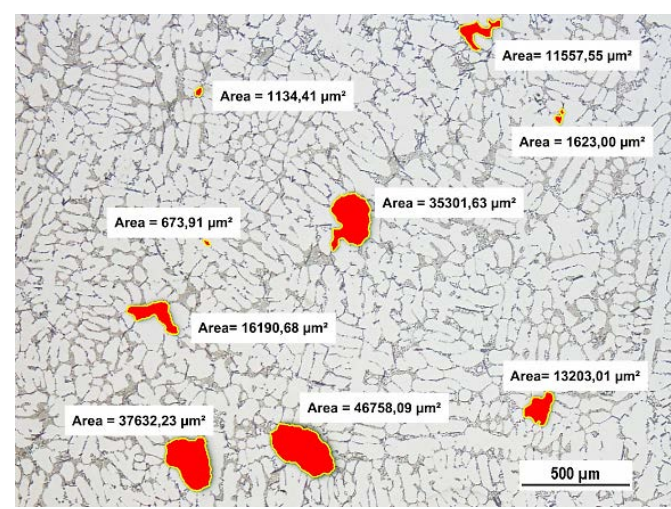

c) $0.655 \% \mathrm{Fe}$.

Fig. 1. Effect of iron on surface porosity
A change in pore morphology from discrete isolated pores to spongy interdendritic pores occurs even at small, additions of iron (Fig. 1).

\section{Conclusion}

Addition of higher amount of $\mathrm{Fe}$ to the secondary AlSi7Mg0.3 alloy showed the results:

0 the surface porosity level decreases with iron content until a minimum value occurs at 0.454 $\% \mathrm{Fe}$. As further iron additions are made, the overall porosity level increases;

0 the pores have been found near to Fe-phases;

o a change in pore morphology from discrete isolated pores to spongy interdendritic pores occurs even at small, additions of iron $(0.123$ $\%)$;

o we can predict, that with the increasing amount of pores are decreasing the mechanical properties.

\section{Acknowledgements}

This research has been supported by the Slovak Research of the project VEGA 1/0533/15 and KEGA 049ŽU-4/2017.

\section{References}

[1] Das, Subodh K., Yin, W., The Worldwide Aluminum Economy: The Current State of the Industry, JOM, 11, 2007. pp. 57-63.

[2] Aluminium Recycling in Europe - The Road to High Quality Products. European Aluminium Association (EAA) and the Organisation of European Aluminium Refiners and Remelters (OEA).

[3] Kuchariková, L. et all., Recycling and properties of recycled aluminium alloys used in the transportation industry, Transport problems, 11, 2, 2016. pp. 117-122.

[4] Tillová, E., Chalupová, M., Hurtalová, L., Belan, J., Manufacturing Technology, 15 (4), 2015. pp. 720-727.

[5] Taylor, J. A., Iron-containing intermetallic phases in Al-Si based casting alloys, Procedia Materials Science 1, 2012. pp. 19-33.

[6] Taylor, J.A. et all., The Role of Iron in the Formation of Porosity in Al-Si-Cu-Based Casting Alloys: Part I. Initial Experimental Observations, Metallurgical and Materials Transactions A, 30A, 6, 1999. pp. 1643-1650. 